\title{
Summer talks in Santiago III - the Politzer Conference
}

\author{
Alejandro Toro-Labbé • Jane S. Murray
}

Published online: 7 June 2013

(C) Springer-Verlag Berlin Heidelberg 2013

The seeds for the Politzer Conference were planted in Santiago, Chile in 2010 by Alejandro Toro-Labbé, Soledad Gutiérrez-Oliva, Barbara Herrera and Felipe Bulat. Behind the scenes, they invited many friends and colleagues of Peter Politzer to come to Santiago, Chile in January 2012 for a conference that was being described as Summer Talks in Santiago III (STS-III). As background, it should be mentioned that Professor Toro-Labbé had previously organized two mini-symposia with the same name, STS-I and STS-II. This one was to be different, a five day meeting with speakers and participants coming from many countries: Argentina, Belgium, Canada, Chile, Colombia, Czech Republic, France, Germany, India, Italy, Mexico, Netherlands, Peru, Poland, Spain, Sweden and the USA.

One of the many things that made this conference unique was that the honoree, Peter Politzer, was kept unaware of the upcoming event until the day that STS-III actually began and was transformed into the Politzer Conference, on the morning of January 9, 2012. Keeping this secret from Peter was made easier by the fact that he tends to not be very observant, and missed a lot of clues that might have spoiled the surprise. But it turned out to be indeed a great surprise for him (but only for him; even his daughters in Atlanta and brother in San Diego knew about it)!

Peter Politzer was born in Prague, Czechoslovakia, but grew up primarily in the United States, in Cleveland, Ohio. Peter received all of his degrees from Western Reserve University; his Ph.D. dissertation, directed by Ralph

\footnotetext{
A. Toro-Labbé

Pontificia Universidad Catolica de Chile,

Santiago, Chile

e-mail: atola@uc.cl

J. S. Murray $(\bowtie)$

University of New Orleans, New Orleans, LA, USA

e-mail: jsmurray@uno.edu
}

Petrucci, dealt with the chemisorption of $\mathrm{CO}$ on metals and metal oxides, an area that he found really intriguing. After two very pleasant and fruitful years as a research associate with Harrison Shull at Indiana University, Peter joined the chemistry faculty at Louisiana State University in New Orleans (later renamed the University of New Orleans) in 1966. He thought that he would remain for a few years and then go elsewhere. But New Orleans is a fascinating city and UNO provided a stimulating, dynamic environment - so he stayed. Peter was awarded the rank of Boyd Professor in 1993. He retired from teaching in 2006 due to Hurricane Katrina, but he continues to be as active as ever in research, now holding the title of Boyd Professor Emeritus.

In December, 2003, Peter and Jane Murray accepted Alejandro Toro-Labbé's kind invitation to spend a week with his research group at the Pontificia Universidad Catolica de Chile in Santiago. The visit was so enjoyable and so productive that they began to come every year, and to stay longer each time. The conference in January 2012 represented their ninth trip to Santiago, and they remained for more than five weeks. (This should be a warning to Alejandro, when he issues future invitations!)

The Politzer Conference spanned the week of January 9-13, 2012, beginning with an introductory talk given by Alejandro which included, in an entertaining fashion, a number of segments from Peter's life. This was followed by three sessions of talks during the day and a wonderful reception on site in the evening. The following days included sessions with a variety of stimulating talks and posters and a Chilean barbeque on Thursday evening. Alejandro closed the meeting on Friday, after Jane and Peter delivered the final talks of the conference. He and Soledad then fled to the hills (actually to the Cordilleras de los Andes)! This Special Issue of the Journal of Molecular Modeling is dedicated to Peter Politzer.

Written by: The Special Issue Editors, Alejandro Toro-Labbé and Jane S. Murray 